\title{
The Strategy Research of Presale and the Refounding of Real Estate Market
}

\author{
Min $\mathrm{Xu}^{1, \mathrm{a}}$ \\ ${ }^{1}$ School of Management, Hefei University of Technology, Hefei, Anhui, 230041
}

\section{Keywords: Real Estate; Presale; Refunding}

\begin{abstract}
This article will divide the commercial residential building into two phrase: advance sele and normal sale. At the same time, this paper analyses the relationship between the marketing demand and supply, in order to make the optimum price strategy. Considering the behavior that the consumers decide to refund the house, this article analyses what actions the real estate investor take in different conditions. After researching, we find that the coefficient of consumers affected the advance selling policy and benefit of a real estate investor with the value of the commercial residential building is descendsing.
\end{abstract}

\section{Introduction}

The real estate industry is usually used for presale sales for consumers, that is, real estate development enterprises will be under construction in the pre-sold to consumers and consumers pay the principal behavior, but because of the delivery of housing due to quality, and design is not In order to alleviate and eliminate consumer concerns about the sale of housing, April 15, 2015, Evergrande Real Estate Group held a press conference and announced that since April 16, 2015 onwards, The face of the National Evergrande real estate all residential customers, the full implementation of no reason to check out, that is, buyers in the signing of commercial housing business at the same time, customers and Evergrande signed no reason to withdraw from the agreement, check-in before check-out . Hengda for the first time will be returned to the real estate industry, is the real estate industry innovation move. With a second-tier cities, real estate prices continue to rise, Hengda real estate sales in 2015 reached 200 billion, 2016 as of September sales reached 2805.8 However, with the real estate market continues to heat up, in order to promote its sustained and healthy development, since September 30, 2016, the country has issued a number of hot cities in the limited number of loans, but also to the end of the year, , Such as the purchase of real estate regulation and control policies in the new situation, Evergrande real estate need to continue to maintain "no reason to return" strategy? Real estate enterprises in the face of the differentiated market environment, how to carry out Presale and Refunding the decision - making mechanism needs to be sorted out.

Domestic and foreign scholars for the Presale and Refunding issues such as the study, Xie [1] and Zhao [2] and others who studied the manufacturers when the presale and how to presale problems, and according to the consumer's risk aversion preferences put forward retail Businessmen do not provide presale, to provide a presale with a moderate discount and provide a deep discount of the presale three presale strategy in the consumer product valuation, Prasad [3], Zeng [6] and Li [7] And others believe that presale can help retailers reduce the uncertainty of demand, they will be the consumer's valuation of the product is divided into certainty and uncertainty, the study of the presale, normal sales and presale and then normal sales In the category of consumer types, Swinney [4] divides consumers into hyperopia consumers and myopia consumers, Nocke [5] that consumers can be divided into the valuation of products and low valuation of two Type .Lim [8] and others based on the market demand is known under the premise of the study with hyperopia consumers, myopia consumers and speculators of the presale market, and the presale market is divided into product appreciation market and product depreciation market, Found that the existence of speculators can give retailers a certain profit and in the presale stage speculators and hyperopia consumers purchase decision is consistent in the consumer returns, Wang Junping [9] and others online sales for easy online The problem of optimal ordering of supply chain is studied by a 
two-stage dynamic programming to describe the two order behaviors of online sellers in the dynamic market environment. In addition, both the presale and the consumer In the research of return problem, Li Yongjian [10] and Zhang Fuli [11] studied the presale strategy and the defect-free return of the newsboy retailer under the premise that the product demand and the consumer valuation were uncertain.

Based on this, this paper considers the presale and the normal sales of sales patterns and consumer returns, based on the premise of the depreciation of commercial housing, under the premise of analysis of market supply and demand, to find the real estate business's optimal pricing strategy and the best profit.

\section{Presale and Refunding Decision-Making Basic Model}

Basic Model Analysis. In the presale phase, the real estate business supply for the unit $K$, the unit cost of the market there are a number of real estate valuation for the buyers, real estate developers through the identification of a variety of ways to participate in presale of consumers The real estate business will usually be listed in batches, assuming that the initial supply for the (and), when the presale phase after the end of the purchase of real estate buyers did not enter the normal sales stage ; Real estate business in the presale and normal sales stage of the price of commercial housing were $p_{1} \leq \min \left\{E\left(v_{1}\right), E\left(p_{2}\right)\right\}$, and buyers in the presale stage to buy commercial housing decision-making basis is that some consumers in the presale phase to complete the purchase, which also take into account the return of funds for real estate The daily operating cash flow of the firm has an important effect, and the utility of the profit obtained in the presale phase has a magnifying effect, so that the utility increase coefficient is.

In the normal sales stage, the number of buyers in the presale phase is the number of buyers in the normal sales stage $W-q_{1}$. The valuation of the purchasers in the normal sales phase is $v_{2}$ that the purchaser's decision to purchase the commercial housing in the normal sales stage is $p_{2} \leq E\left(v_{2}\right)$.

At the same time, in the presale phase has been the purchase of commercial housing users have $\lambda q_{1}(0 \leq \lambda<1)$ on the purchase of housing is not satisfied and asked to return. After the end of the two stages, if the real estate business there are remaining commercial housing, the manufacturer can be the value of commercial housing The price of the remaining commercial housing, such as the occasional real estate business will not be sold at a lower price to deal with their suppliers to hedge the purchase price $\underline{v}<\min \left\{E\left(v_{1}\right), E\left(v_{2}\right)\right\}$, which in summary, the real estate business decision-making function

$$
U=p_{1}(1+\theta)(1-\lambda) q_{1}+p_{2} q_{2}+\max \left\{K-(1-\lambda) q_{1}-q_{2}, 0\right\} \underline{v}-K c
$$

For taking into account the size of the relationship between the real estate market, the market can be divided into the buyer market ( $K \geq W$ ) and the seller's market ( $K<W$ ) two types, the use of superscript below $c$ the buyer's market, superscript $S$ is that the seller's market.

\section{Pre sale Decision -Making Model for Real Estate}

Supply Greater than the Demand Scene $(K \geq W)$. In this context, the real estate business two-stage utility function is:

In this context, the real estate business two-stage utility function is:

$$
U^{c}=p_{1}(1+\theta)(1-\lambda) q_{1}+p_{2} q_{2}+\left(K-(1-\lambda) q_{1}-q_{2}\right) \underline{v}-K c
$$

Theorem 1 When the consumer's return rate $\lambda \in\left[0, \lambda_{1}\right]$ is satisfied, the real estate business in the presale phase and the normal sales stage of the pricing $\left(p_{1}^{c}, p_{2}^{c}\right)=\left(E\left(v_{2}\right), E\left(v_{2}\right)\right)$, two-stage sales $\left(q_{1}^{c}, q_{2}^{c}\right)=(W, 0)$; if the real estate $\lambda \in\left(\lambda_{1}, 1\right)$ business may not use the presale strategy or in the presale period $p_{1}^{c}>E\left(v_{1}\right)$ will raise prices to normal the sales phase price $p_{2}^{c}=E\left(v_{2}\right)$ is defined as 
two-stage sales $\left(q_{1}^{c}, q_{2}^{c}\right)=(0, W)$ for which $\lambda_{1}=\frac{E\left(v_{2}\right) \theta}{E\left(v_{2}\right)(1+\theta)-\underline{v}}$.

The proof is to determine the normal sales phase of the relevant decision-making, and then solves the presale phase of the relevant decision-making.

In the normal sales stage, it is assumed that some buyers have to go out of the house because of the decline in property prices or dissatisfaction with the house and the supply of houses is changed to the supply of the house $K-(1-\lambda) q_{1}^{c}$, which is still greater than the demand. So the real estate business pricing strategy is still $p_{2}^{c}=E\left(v_{2}\right)$, the number of housing sales $q_{2}^{c}=W-q_{1}^{c}$.

$p_{2}^{c}=E\left(v_{2}\right), q_{2}^{c}=W-q_{1}^{c}$ Will be substituted into the formula (2), simplified available

$$
U^{c}=E\left(v_{2}\right) W+\left[p_{1}^{c}(1+\theta)(1-\lambda)-E\left(v_{2}\right)\right] q_{1}^{c}+\left(K-W+\lambda q_{1}^{c}\right) \underline{v}-K c
$$

By the utility function (3) we can see $\frac{d U^{c}}{d q_{1}^{c}}=p_{1}^{c}(1+\theta)(1-\lambda)-E\left(v_{2}\right)+\lambda \underline{v}$, so $p_{1}^{c} \geq \frac{E\left(v_{2}\right)-\lambda \underline{v}}{(1+\theta)(1-\lambda)}$ the real estate business will take the presale strategy and $\frac{d U^{c}}{d p_{1}^{c}}=(1+\theta)(1-\lambda) q_{1}^{c}>0$ the formation of sales; and presale stage consumer purchase decision is $p_{1}^{c} \leq \min \left\{E\left(v_{1}\right), E\left(p_{2}\right)\right\}$ based on, and $E\left(v_{1}\right)>E\left(v_{2}\right)$ that the existence of real estate developers $\lambda \in\left[0, \lambda_{1}\right]$ in the presale stage of pricing, Which $\lambda_{1}=\frac{E\left(v_{2}\right) \theta}{E\left(v_{2}\right)(1+\theta)-\underline{v}}$, as we can see $\underline{v}<\min \left\{E\left(v_{1}\right), E\left(v_{2}\right)\right\}$.

Supply Less than the Demand Scene $(K<W)$. Theorem 2 At that time $\lambda \in\left[0, \frac{W-K}{K}\right]$, the real estate business in the presale phase and the normal sales stage of the $\operatorname{pricing}\left(p_{1}^{s_{1}}, p_{2}^{s_{1}}\right)=\left(E\left(v_{2}\right), E\left(v_{2}\right)\right)$ for the two - stage sales $\left(q_{1}^{s_{1}}, q_{2}^{s_{1}}\right)=(K, \lambda K)$.

Theorem 3 At that time $\lambda \in\left[\frac{W-K}{K}, \lambda_{1}\right]$, the real estate business of the presale phase with the normal sales stage of the pricing strategy $\left(p_{1}^{s_{2}}, p_{2}^{s_{2}}\right)=\left(E\left(v_{2}\right), E\left(v_{2}\right)\right)$ for the two - stage sales $\left(q_{1}^{s_{2}}, q_{2}^{s_{2}}\right)=(K, W-K)$ for which $\lambda_{1}=\frac{E\left(v_{2}\right) \theta}{E\left(v_{2}\right)(1+\theta)-\underline{v}}>\frac{W-K}{K}$.

In this context, because the normal sales stage of the relationship between the number of housing demand $W-q_{1}^{s}$ and the number of supply exists $K-(1-\lambda) q_{1}^{s}$ with the two cases, respectively, $W-K \geq \lambda q_{1}^{s}$ and $W-K<\lambda q_{1}^{s}$ the use of superscript and logo related variables.

$$
W-K \geq \lambda q_{1}^{s}
$$

At this point, the real estate business two-stage utility function:

$$
U^{s}=p_{1}(1+\theta)(1-\lambda) q_{1}+p_{2} q_{2}-K c
$$

The number of buyers on the market in the normal sales stage is $W-q_{1}^{s_{1}}$ that the supply of the market is $K-(1-\lambda) q_{1}^{s_{1}}$, and the market is converted into supply-related decisions $p_{2}^{s_{1}}=E\left(v_{2}\right)$. We can see that the real estate sales in the normal sales stage $q_{2}^{s_{1}}=K-(1-\lambda) q_{1}^{s_{1}}$, the number of sales of housing.

$$
\begin{aligned}
& p_{2}^{s_{1}}=E\left(v_{2}\right), q_{2}^{s_{1}}=K-q_{1}^{s_{1}}+\lambda q_{1}^{s_{1}} \text { simplified available: } \\
& U^{s_{1}}=E\left(v_{2}\right) K+\left[p_{1}^{s_{1}}(1+\theta)-E\left(v_{2}\right)\right](1-\lambda) q_{1}^{s_{1}}-K C
\end{aligned}
$$


According to the utility function $\frac{d U^{s_{1}}}{d q_{1}^{s_{1}}}=\left[p_{1}^{s_{1}}(1+\theta)-E\left(v_{2}\right)\right](1-\lambda)$, we can see that $E\left(v_{1}\right)>E\left(v_{2}\right)$ the process can be deduced by the reference and theorem 1 in the presale phase $p_{1}^{s_{1}}=E\left(v_{2}\right)$ and the sales price of the salesman. If this is the case,

(2) $W-K<\lambda q_{1}^{s}$

The two-stage utility function of the real estate business is $U^{s_{2}}$ transformed into equation (2).

With reference to theorem 1 and 2 to prove the process, the real estate business in the normal sales stage of the pricing $p_{2}^{s_{2}}=E\left(v_{2}\right)$; at the same time that exists $\lambda \in\left[\frac{W-K}{K}, \lambda_{1}\right]$, the real estate business presale pricing $p_{1}^{s_{2}}=E\left(v_{2}\right) \in\left[\frac{E\left(v_{2}\right)-\lambda \underline{v}}{(1+\theta)(1-\lambda)}, E\left(v_{1}\right)\right]$, this time $\left(q_{1}^{s_{2}}, q_{2}^{s_{2}}\right)=(K, W-K)$.

Inference 1 When the market is in a downtrend $\max \left(\lambda_{1}, \frac{W-K}{K}\right)<\lambda<1$, if the real estate business will not use the presale strategy or the presale price is higher than $E\left(v_{1}\right)$ the delay in the sale of all the houses to the normal sales stage $p_{2}^{d s}=E\left(v_{2}\right),\left(q_{1}^{d s_{2}}, q_{2}^{d s_{2}}\right)=(0, W)$ this will take the presale strategy.

Proof See the theorem 1 proof process, the supply is greater than the demand situation, the utility of the utility

$$
U^{d c}=\left\{\begin{array}{cc}
E\left(v_{2}\right)(1+\theta)(1-\lambda) W+(K-(1-\lambda) W) \underline{v}-K c & 0 \leq \lambda \leq \lambda_{1} \\
E\left(v_{2}\right) W+(K-W) \underline{v}-K c & \lambda_{1}<\lambda<1
\end{array}\right.
$$

See the theorem 3, 4 proof process, in the supply of less than the demand situation, the effectiveness of real estate developers

$$
U^{s}=\left\{\begin{array}{cc}
\left(E\left(v_{2}\right)+E\left(v_{2}\right) \theta(1-\lambda)-c\right) K & 0 \leq \lambda \leq \frac{W-K}{K} \\
E\left(v_{2}\right) W+\left[E\left(v_{2}\right)(1+\theta)(1-\lambda)-E\left(v_{2}\right)\right] K+(K-W+\lambda K) \underline{v}-K c & \frac{W-K}{K}<\lambda \leq \max \left(\frac{W-K}{K}, \lambda_{1}\right) \\
E\left(v_{2}\right) K+(W-K) \underline{v}-K c & \max \left(\frac{W-K}{K}, \lambda_{1}\right)<\lambda<1
\end{array}\right.
$$

\section{Numerical Analysis}

In order to compare the analysis to facilitate the quantitative description of the above two kinds of sales strategy, assuming that the parameters of the market $\theta=0.3, \lambda=0.35, k=0.4, E\left(v_{1}\right)=130, E\left(v_{2}\right)=100, \underline{v}=5, c=5, K=1000$ when the supply $W=800$ is greater than the demand $W=1200$, when the supply is less than the demand.

Keep the other parameters unchanged, from 0.1 to 0.6. At this point in the market situation, the retailer in the supply is greater than the demand and supply less than the demand for the benefits of the situation shown in Figure 1, from the figure that the real estate developers in the less than the benefits of the situation is higher than the benefits of oversupply, There are two thresholds for the under-seeking scenario $\frac{W-K}{K}$ and $\lambda_{1}$, where the benefits $0 \leq \lambda \leq \lambda_{1}$ are gradually reduced and the decrease $\left(\left[0, \frac{W-K}{K}\right]\right)$ is less than the decrease $\left(E\left(v_{2}\right) \theta K\right)$, at which time the real estate agent to cancel the presale strategy $\left[\frac{W-K}{K}, \lambda_{1}\right]$ and thus the benefits tend to be flat $\left(E\left(v_{2}\right)(1+\theta)-\underline{v}\right) K$. In 
the oversupply scenario $\left(E\left(v_{2}\right)(1+\theta)-\underline{v}\right) K$, There is a critical value $\lambda_{1}$, when the benefits gradually decline $0 \leq \lambda \leq \lambda_{1}$, when $\lambda_{1}<\lambda$, the real estate business to cancel the presale strategy makes the benefits tend to flat.

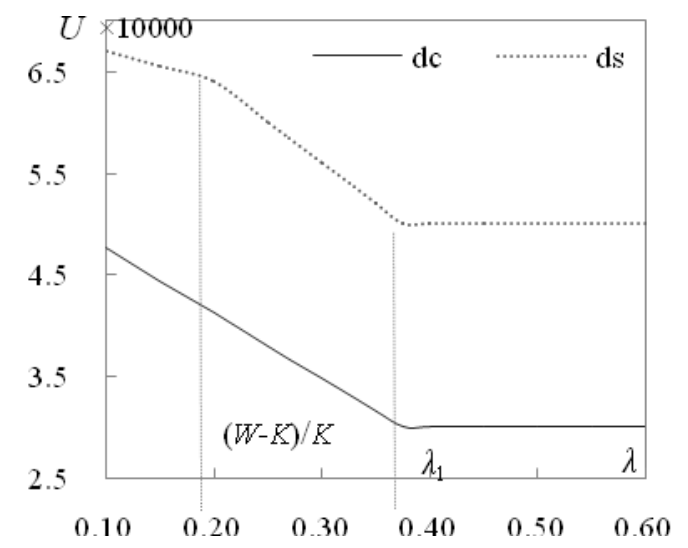

Figure 1 Benefits coefficient of $\lambda$ with the change

\section{Conclusion}

Based on the analysis of the size of supply and demand in the real estate market, the optimal pricing and presale strategy of the real estate business in different market conditions is analyzed by analyzing the relationship between supply and demand in the real estate market. And the optimal benefits, and put forward the real estate developers to accept the home buyers check out the strategy, in the real estate market downturn situation, the real estate business benefits with the consumer returns rate decreased, and in the supply of less than the demand conditions, of the utility is greater than the supply is greater than the demand conditions.

There are many aspects of this article can be extended, we can first consider the presale stage of the normal sales stage of the impact, that is, after the end of the presale phase will be part of the new buyers into the normal sales stage. Secondly in the presale and normal sales Two-stage join speculators, through speculators and real estate business competition between the real estate developers to change the two-stage pricing strategy and thus affect the real estate business strategy choice.

\section{References}

[1] Xie J H, Shugan S M. Electronic tickets, smart cards, and online prepayments: when and how to advance sell [J]. Marketing Science, 2001, 20: 219-243

[2] Zhao X, Stecke K E. Pre-orders for new to-be-released products considering consumer loss aversion [J]. Production and Operations Management, 2010, 19: 198-215.

[3] Prasad A, Stecke K E, Zhao X. Advance selling by a newsvendor retailer [J]. Production and Operations Management, 2011, 20: 129-142

[4] Swinney R. Selling to strategic consumers when product value is uncertain: the value of matching supply and demand [J]. Management Science, 2011, 57: 1737-1751

[5] Nocke V, Martin P, Frank R. Advance-purchase discounts as a price discrimination device [J]. Journal of Economic Theory, 2011, 146: 141-162

[6] Zeng C H. Optimal advance selling strategy under price commitment [J]. Pacific Economic R eview, 2013, 18: 233-258.

[7] Li C H, Zhang F Q. Advance demand information, price discrimination, and pre - order strategies [J]. Manufacturing and Service Operations Management, 2013, 15: 57-71. 
[8] Lim.Advance Selling in the Presence of Speculators and Forward-looking Consumers [J]. Production and Operations Management, 2013, 19: 571-587.

[9] Wang Junping, Yang Jianbo, Jia Zhaoli. Supply chain coordination model for online sales of perishable goods based on defect - free return [J]. China Management Science, 2013 (6): 47-56

[10] Li Yongjian, Xu Lei, Yang Xiaoli. Product presale, return policy and consumer defect-free return behavior [J]. Nankai Management Review, 2012 (5): 105-113

[11] Zhang Fuli, Zheng Di. Study on retailer's return strategy based on presale and uncertain demand [J]. Journal of Nanjing Institute of Auditing, 2015 (6): 75-84 